\title{
Hepatic Hydrothorax in the Absence of Ascites: A Diagnostic Challenge
}

\author{
Sangita Kamath ${ }^{1}$, Ashok Sunder ${ }^{1}$ \\ 1. Internal Medicine, Tata Main Hospital, Jamshedpur, IND
}

Corresponding author: Sangita Kamath,dr.sdkamath@gmail.com

\begin{abstract}
Hepatic hydrothorax is a rare complication of chronic liver disease. It usually occurs in patients with advanced liver disease, portal hypertension, and ascites. On a rare instance, it may be the index presentation of chronic liver disease. Hepatic hydrothorax occurs in approximately $5-6 \%$ of patients with cirrhosis. The exact mechanism has not been well defined, but it is frequently thought to be due to the direct passage of ascitic fluid from the peritoneal cavity through the diaphragmatic defects. Treatment involves salt and water restriction and diuretics. Therapeutic thoracocentesis is required in case of respiratory distress. In resistant cases, indwelling pleural catheter (IPC) like PleurX catheter system (Franklin Lakes, NJ: BD) is placed and patients manage their symptoms through intermittent drainage of the pleural fluid. Here we describe an unusual case of hepatic hydrothorax in a patient with rheumatoid arthritis and liver cirrhosis without any ascites, a scenario that has rarely been reported in the literature. The patient underwent thoracentesis thrice but in view of re-accumulating pleural effusion, a pig-tail catheter with underwater seal was inserted. She was then referred to a hepatology center for transjugular intrahepatic portosystemic shunt (TIPS) or liver transplant.
\end{abstract}

Review began 07/09/2021 Review ended 07/12/2021 Published 07/26/2021

(c) Copyright 2021

Kamath et al. This is an open access article distributed under the terms of the Creative Commons Attribution License CC-BY 4.0., which permits unrestricted use, distribution, and reproduction in any medium, provided the original author and source are credited.
Categories: Internal Medicine, Gastroenterology, Pulmonology

Keywords: hydrothorax, pleural effusion, cirrhosis, liver, ascites

\section{Introduction}

Ascites is a common clinical finding in patients with advanced liver disease with portal hypertension. In about $5-10 \%$ of cases, they may develop pleural effusion due to the trans-diaphragmatic movement of ascitic fluid across the pores in the diaphragm. Hepatic hydrothorax is the excessive $(>500 \mathrm{~mL})$ accumulation of transudate in the pleural cavity in such patients with decompensated liver cirrhosis in the absence of cardiopulmonary and renal causes [1]. In rare cases, when the rate of production is less than the absorptive capacity of the peritoneum but more than that of pleura, pleural effusion may develop in the absence of ascites due to negative intrathoracic pressure and diaphragmatic defects. The diagnosis is evident in the presence of known liver disease but might prove more challenging in the absence of history of liver disease. Here we report a rare case of a patient with rheumatoid arthritis and obesity who presented with large transudative pleural effusion in absence of ascites creating a diagnostic dilemma.

\section{Case Presentation}

A 50-year-old lady was admitted to our hospital with a history of gradually progressive breathlessness of one-month duration associated with right-sided chest heaviness and mild dry cough. The patient was unable to lie flat without becoming dyspneic. She was a known case of seronegative rheumatoid arthritis (RA) detected two years back and was on oral methotrexate 10 milligram $(\mathrm{mg})$ once per week, tablet sulfasalazine $500 \mathrm{mg}$ twice daily, tablet prednisolone $10 \mathrm{mg}$ once daily, and tablet etoricoxib $90 \mathrm{mg}$ as required. She had no history of fever.

On admission, she was coherent and tachypneic with a respiratory rate of 34 breaths/minute with accessory muscles of respiration working. She had mild pallor but no signs of icterus, clubbing, lymphadenopathy, or pedal edema. There were no other peripheral signs of chronic liver disease. Her body mass index (BMI) was $29.4 \mathrm{~kg} / \mathrm{m}^{2}$. She was afebrile, her pulse rate was $112 /$ minute, and her blood pressure was $146 / 82 \mathrm{mmHg}$. Her respiratory system examination was normal on the left side while on the right revealed reduced chest expansion, stony dull note on percussion, and reduced air entry consistent with right-sided pleural effusion. Examination of the cardiovascular, gastrointestinal, and neurological systems was within normal limits. There were no dilated veins on the abdominal wall. Her initial blood investigations on admission are as shown in Tables 1,2. 


\section{Cureus}

\begin{tabular}{|c|c|c|}
\hline Parameter & On admission & Normal range \\
\hline Hemoglobin $(\mathrm{g} / \mathrm{dL})$ & 10.2 & 11.5-16.5 \\
\hline TLC (cells per $\mathrm{mm}^{3}$ ) & 4900 & $4000-11,000$ \\
\hline MCV (fL) & 93.6 & $80-100$ \\
\hline Platelet count (cells per $\mathrm{mm}^{3}$ ) & 98,000 & $150,000-450,000$ \\
\hline Reticulocyte count (\%) & 1.1 & $0.5-1.5$ \\
\hline Serum LDH (U/L) & 533.7 & $140-280$ \\
\hline Total serum protein (g/dL) & 6.7 & $6.6-8.3$ \\
\hline Serum albumin (g/dL) & 3.07 & $3.5-5.2$ \\
\hline Serum globulin (g/dL) & 3.63 & $2.5-3.5$ \\
\hline Serum creatinine $(\mathrm{mg} / \mathrm{dL})$ & 0.98 & $0.5-1.5$ \\
\hline Total bilirubin (mg/dL) & 0.95 & $0.2-1$ \\
\hline Direct bilirubin (mg/dL) & 0.7 & $0.1-0.5$ \\
\hline ALT (U/L) & $27.1 \mathrm{U} / \mathrm{L}$ & $5-40$ \\
\hline AST (U/L) & $94.8 \mathrm{U} / \mathrm{L}$ & $5-45$ \\
\hline ALP (U/L) & $140.8 \mathrm{U} / \mathrm{L}$ & $35-125$ \\
\hline PT (seconds) & 14 & $11-15$ \\
\hline
\end{tabular}

\section{TABLE 1: Laboratory investigations of the patient on the day of admission}

TLC: total leukocyte count; MCV: mean corpuscular volume; LDH: lactate dehydrogenase; ALT: alanine transaminase; AST: aspartate aminotransferase; ALP: alkaline phosphatase; PT: prothrombin time

\begin{tabular}{|c|c|c|}
\hline Investigations & Values & Normal range \\
\hline Antibodies to anti-nuclear antigen (ANA) & Not detected & \\
\hline Antibodies to double-stranded DNA (dsDNA) - ELISA & Not detected & \\
\hline Rheumatoid factor (RA) & Negative & \\
\hline Anti-citrullinated antibodies (anti-CCP) & Negative & \\
\hline Anti-thyroid peroxidase (TPO) antibodies & $1.27 \mathrm{IU} / \mathrm{L}$ & $<9 \mathrm{IU} / \mathrm{L}$ \\
\hline Serum TSH (CLA) & $3.64 \mu \mathrm{IU} / \mathrm{L}$ & $0.3-4.5 \mu \mathrm{lU} / \mathrm{L}$ \\
\hline HBsag & Negative & \\
\hline Anti-HCV antibodies & Non-reactive & \\
\hline Antibodies to HIV 1 and 11 & Non-reactive & \\
\hline Anti-smooth muscle antibody (ASMA) & Negative & \\
\hline
\end{tabular}

TABLE 2: Lab investigations (hormonal and antibody assay)

TSH: thyroid-stimulating hormone; CLA: chemiluminescent assay; HBsag: hepatitis B surface antigen; HCV: hepatitis C virus 


\section{Cureus}

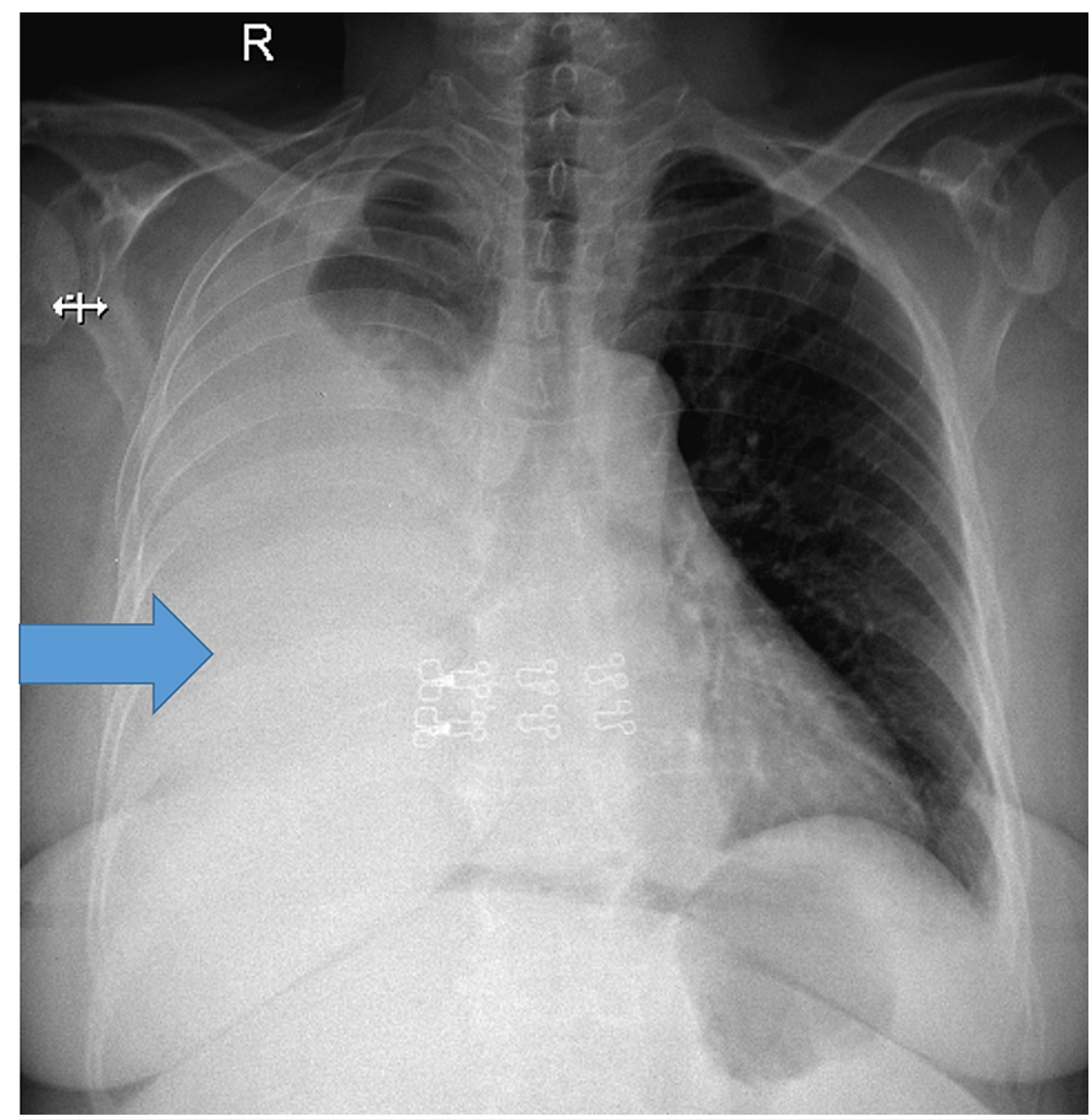

FIGURE 1: Chest radiograph showing massive right pleural effusion

Diagnostic tapping of pleural fluid was done. It was pale yellow colored and showed a total of 210 cells with $10 \%$ neutrophils, $50 \%$ lymphocytes, 30\% mesothelial cells, glucose $124 \mathrm{mg} / \mathrm{dL}$ (corresponding blood glucose was $130 \mathrm{mg} / \mathrm{dL}$ ), LDH $71.6 \mathrm{U} / \mathrm{L}$, proteins $0.9 \mathrm{~g} / \mathrm{dL}$, albumin $0.4 \mathrm{~g} / \mathrm{dL}$, adenosine deaminase (ADA) $2.5 \mathrm{U} / \mathrm{L}$. Smear revealed few neutrophils and mesothelial cells. Malignant cells and parasites were not found. Cultures for bacteria and fungi were negative. Pleural fluid was transudate as per Light's criteria. Cellblock of pleural fluid did not show any abnormal cells. Gene-Xpert of pleural fluid did not reveal mycobacterium tuberculosis. Ultrasound of her abdomen revealed coarse echotexture of the liver with irregular margins and mild splenomegaly $(12.5 \mathrm{~cm})$. There was no ascites. Doppler ultrasound of portal vein and hepatic veins was normal. In view of early cirrhosis of the liver, an upper gastrointestinal endoscopy was done to look for evidence of portal hypertension. It showed portal gastropathy without evidence of varices. Her brain natriuretic peptide (BNP) was $91.2 \mathrm{pg} / \mathrm{mL}$ (normal range: 100-400 pg/mL). Echocardiography revealed normal left ventricular ejection fraction, no diastolic dysfunction, normal pulmonary artery pressure, and cardiac valves. Her urine albumin-creatinine ratio (ACR) and microscopy were normal. Contrast-enhanced computerized tomography (CECT) of chest showed moderate right pleural effusion with underlying collapsed lung with few infiltrations in left upper lobe. There were no abnormal lymph nodes or any mass. There was no pleural thickening or nodularity (Figures $2 a, 2 b$ ). 


\section{Cureus}

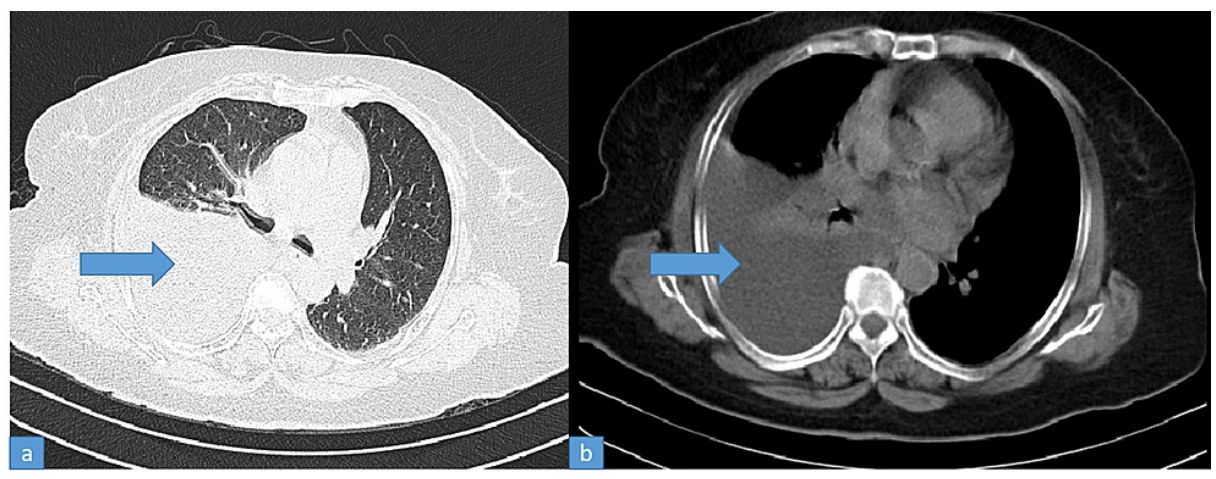

FIGURE 2: CECT thorax showing right pleural effusion - lung (a) and bone (b) windows

CECT: contrast-enhanced computed tomography

A clinical diagnosis of chronic liver disease with model for end-stage liver disease (MELD) score of nine and Child-Pugh class B eight points with hepatic hydrothorax $(\mathrm{HH})$ was made. As she was visibly dyspneic, one liter of pleural fluid was tapped therapeutically. She was also started on intravenous frusemide $40 \mathrm{mg}$ twice daily, oral spironolactone $50 \mathrm{mg}$ twice daily, high protein and low salt $(80 \mathrm{mmol} /$ day) diet. However, there was re-accumulation of the fluid and one liter of pleural fluid was tapped again after three days. In the meantime, her diuretics were escalated to frusemide $120 \mathrm{mg} / \mathrm{day}$ and spironolactone to $200 \mathrm{mg} / \mathrm{day}$ after which she developed hypotension and severe hyponatremia with confusion. Her serum sodium level dropped from $130 \mathrm{mmol} / \mathrm{L}$ to $114 \mathrm{mmol} / \mathrm{L}$. Sodium level was corrected gradually with liberal sodium intake and stopping furosemide for three days. Her blood pressure improved but there was re-accumulation of pleural fluid. Chest X-ray showed a large right pleural effusion. As we do not have facility for intercostal pleural catheter (IPC) placement, a pigtail catheter was introduced under radiological guidance (Figure 3a, 3b) and connected to underwater seal.

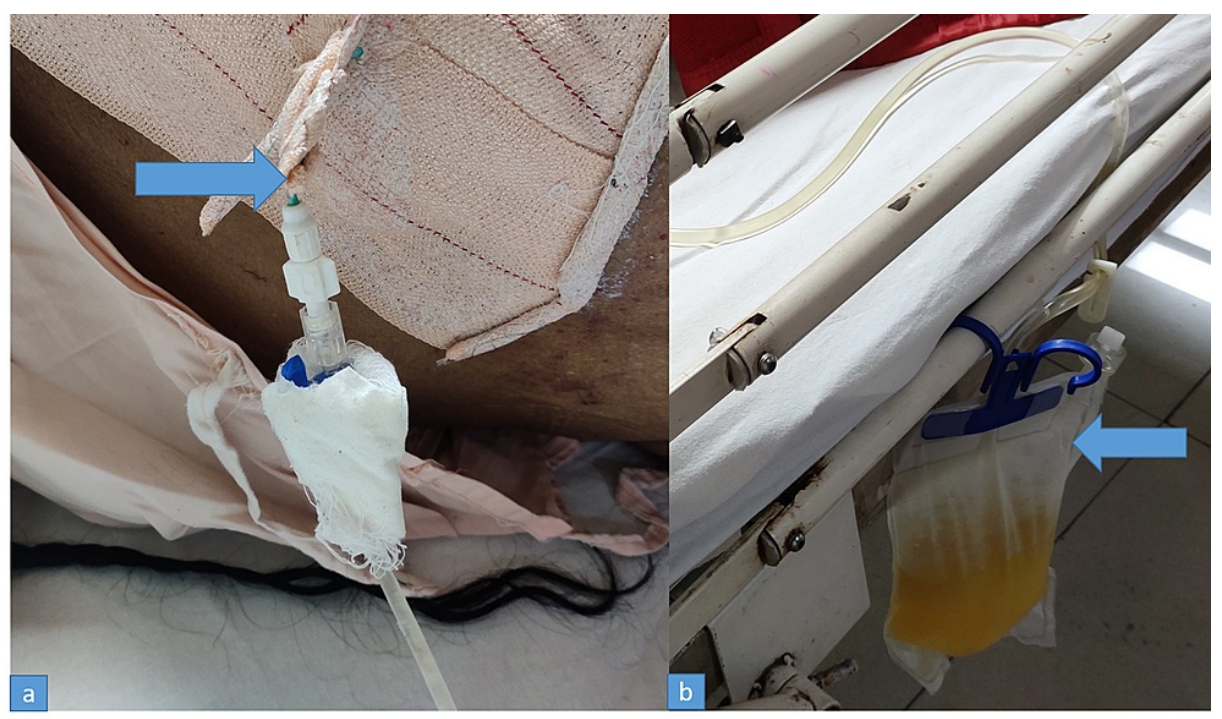

FIGURE 3: Pigtail catheter (a) connected to underwater seal drainage (b)

Two days later, a check chest radiograph showed total drainage of the fluid with complete lung expansion (Figure 4). The patient was then referred to higher hepatology center for further management. 


\section{Cureus}

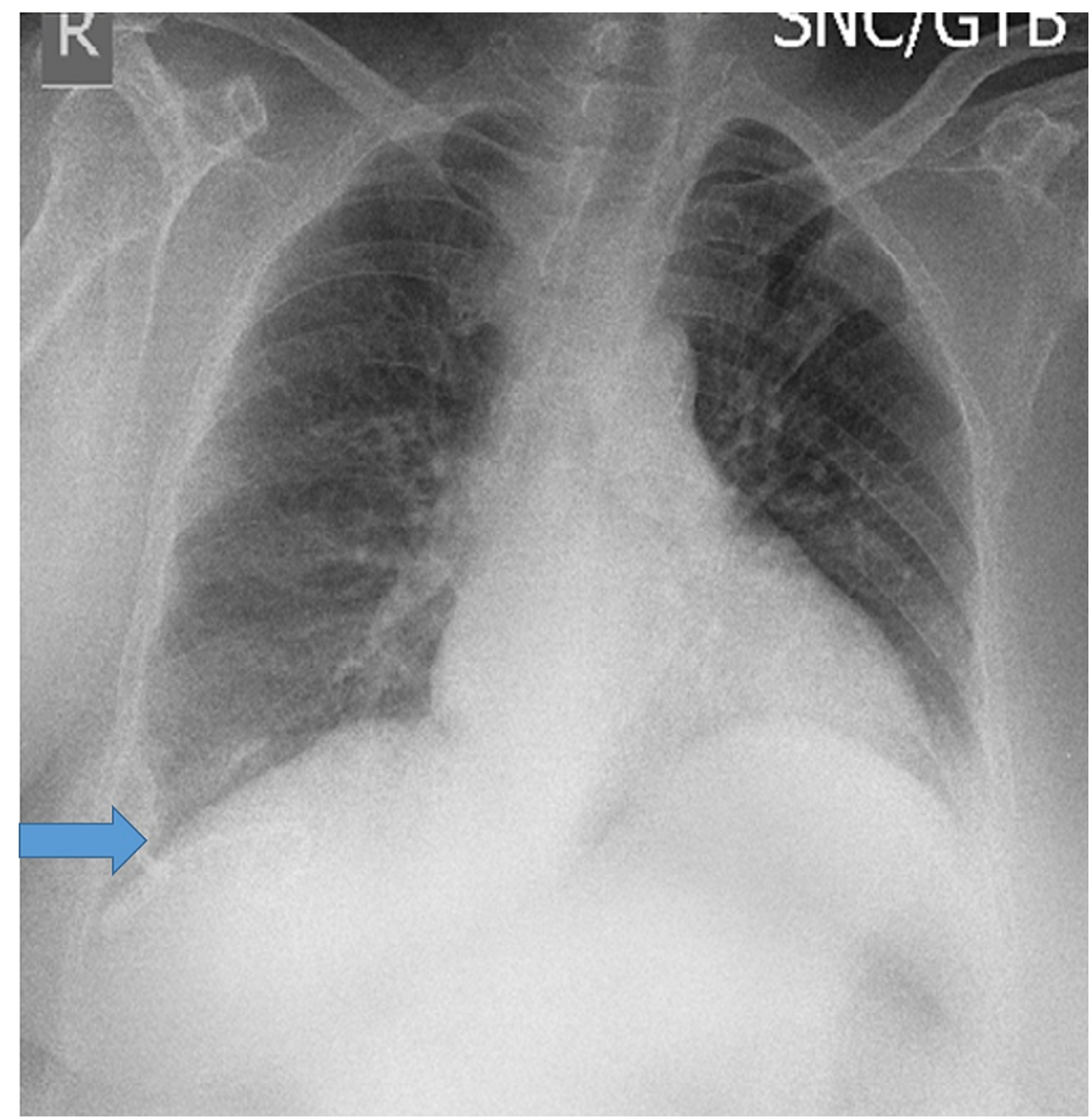

\section{FIGURE 4: Chest radiograph showing complete lung expansion and drainage of pleural fluid}

\section{Discussion}

Hepatic hydrothorax (HH) is defined as a pleural effusion, typically more than $500 \mathrm{~mL}$, in patients with liver disease with portal hypertension without coexisting cardiopulmonary disease [1,2]. In our patient, pleural effusion was transudate and there was no evidence of any cardiac, pulmonary, or renal disease, so the liver disease was thought to be the most probable cause of her right-sided pleural effusion (hepatic hydrothorax). The etiology of the liver disease was uncertain. Considering the patient's BMI, the possibility of nonalcohol-related steato-hepatitis (NASH) seemed likely. Also, she had been on methotrexate for nearly two years for RA, the possibility of methotrexate-induced liver injury leading to acute hepatic decompensation was considered. Differential diagnosis of transudative pleural effusion includes liver failure, renal failure, cardiac dysfunction, urinothorax, and superior vena cava obstruction. Rarely, $5 \%$ of malignant pleural effusions may be transudate [2]. The possibility of RA as a cause of her pleural effusion was thought to be unlikely as RA causes exudative pleural effusion with low glucose content.

Hepatic hydrothorax complicates 5-10\% of end-stage cirrhotic liver disease [3]. The exact mechanism involved is uncertain. However, it is hypothesized that ascites formed due to portal hypertension and hypoalbuminemia, tracks from the peritoneal space to the pleural cavity through trans-diaphragmatic lymphatics or small defects or fenestrations (usually $<1 \mathrm{~cm}$ ) in the diaphragm [4]. The negative intrathoracic pressure of pleural cavity during inspiration and piston-like effect of the diaphragm favors the unidirectional transfer of fluid across these defects. These defects are difficult to detect, as their size varies from $0.03 \mathrm{~mm}$ to $6 \mathrm{~mm}$ in diameter. They are more commonly present on the right diaphragmatic cupola as it is developmentally weaker (less muscular) compared to the left cupola [5]. They can be demonstrated by the unidirectional flow of radiolabeled colloid (human albumin labeled with Technetium 99m) through the diaphragmatic channels [6]. Autopsy studies of patients with hepatic hydrothorax also confirm their presence. The majority ( $85 \%$ ) of hepatic hydrothorax develop on the right, $13 \%$ on the left, and $2 \%$ bilaterally [2]. Hepatic hydrothorax can occur without any detectable ascites, due to higher absorptive capacity of the peritoneum as compared to the pleura [7]. Its occurrence in the absence of ascites is rare but has been reported by John et al. [8]. In a study by Badillo et al. among the 77 cases of $\mathrm{HH}$, seven (9\%) were without 
detectable ascites [9]. Although the development of hydrothorax is not related to a particular cause of cirrhosis, alcoholism is commonly seen in many of these patients.

Depending upon the rapidity and the quantity of accumulation of the fluid, the patient may remain asymptomatic or may present in respiratory distress. The size of the effusion is usually moderate but in $6 \%$ of the cases, it may be massive. Thoracentesis is recommended in cases of respiratory distress, where urgent drainage of hydrothorax is needed. About $21-26 \%$ of patients go on to develop refractory hepatic hydrothorax and may require repeated thoracentesis for symptom control. Medical management includes strict restriction of salt and fluid intake ( $<1 \mathrm{~L} /$ day) and diuretics like combination of loop diuretics and aldosterone antagonist like spironolactone. The dose of the diuretics is gradually titrated upwards till a maximum of $160 \mathrm{mg} / \mathrm{day}$ for frusemide and $400 \mathrm{mg} /$ day for spironolactone is reached. Renal function, electrolytes, and blood pressure should be carefully monitored. However, $20-30 \%$ of patients will have persistent effusion despite optimal treatment. In our case, up-titration of diuretics was limited by hypotension and hyponatremia.

Treatment options in resistant cases include placement of chest tube, indwelling pleural catheter (IPC) like PleurX catheter system (Franklin Lakes, NJ: BD), pig-tail catheter, surgical interventions like video-assisted thoracoscopic surgery (VATS), and trans-jugular intrahepatic portosystemic shunt (TIPS) [6]. As we do not have a facility for PleurX catheter placement, we introduced a pig-tail catheter. A recent meta-analysis by Patil et al. related to the use of IPC for non-malignant effusions demonstrated spontaneous pleurodesis rates of 51\% [10]. TIPS is the most commonly used second-line treatment for refractory effusion [11]. It relieves portal hypertension by decreasing the portosystemic gradient and can lead to significant improvement in fluid accumulation. In a meta-analysis involving 198 patients of hepatic hydrothorax by Ditah et al., complete response to TIPS was seen in $55.8 \%$, partial in $17.6 \%$, and no response in $21.2 \%$ of patients [12]. Liver transplant is the best definitive treatment for refractory $\mathrm{HH}$ and improves long-term survival. The purpose of this presentation is to create awareness of this entity among the clinicians. Although an infrequent cause of transudative pleural effusion, $\mathrm{HH}$ can cause severe respiratory distress and should be kept in mind as a differential diagnosis in patients even without any history of liver disease or ascites.

\section{Conclusions}

A detailed workup is essential to identify and treat the underlying etiology of transudative pleural effusion. Hepatic hydrothorax is a rare complication in patients with decompensated liver disease and may be the initial presentation of cirrhosis. It can also occur in the absence of ascites, leading to a diagnostic dilemma. Like ascites, management of $\mathrm{HH}$ involves strict fluid and sodium restriction and diuretics. However, medical management may not be sufficient to cause complete improvement in all cases and some patients may need thoracentesis or chest tube insertion and early referral to hepatobiliary center for definitive treatment.

\section{Additional Information}

\section{Disclosures}

Human subjects: Consent was obtained or waived by all participants in this study. Conflicts of interest: In compliance with the ICMJE uniform disclosure form, all authors declare the following: Payment/services info: All authors have declared that no financial support was received from any organization for the submitted work. Financial relationships: All authors have declared that they have no financial relationships at present or within the previous three years with any organizations that might have an interest in the submitted work. Other relationships: All authors have declared that there are no other relationships or activities that could appear to have influenced the submitted work.

\section{References}

1. Strauss RM, Boyer TD: Hepatic hydrothorax. Semin Liver Dis. 1997, 17:227-32. 10.1055/s-2007-1007200

2. Sukcharoen K, Dixon S, Mangat K, Stanton A: Hepatic hydrothorax in the absence of ascites . BMJ Case Rep. 2013, 2013:10.1136/bcr-2013-200568

3. Cardenas A, Kelleher T, Chopra S: Review article: hepatic hydrothorax. Aliment Pharmacol Ther. 2004, 20:271-9. 10.1111/j.1365-2036.2004.02081.x

4. Zenda T, Miyamoto S, Murata S, Mabuchi H: Detection of diaphragmatic defect as the cause of severe hepatic hydrothorax with magnetic resonance imaging. Am J Gastroenterol. 1998, 93:2288-9. 10.1111/j.1572-0241.1998.00639.x

5. Chaaban T, Kanj N, Bou Akl I: Hepatic hydrothorax: an updated review on a challenging disease . Lung. 2019, 197:399-405. 10.1007/s00408-019-00231-6

6. Lv Y, Han G, Fan D: Hepatic hydrothorax. Ann Hepatol. 2018, 17:33-46. 10.5604/01.3001.0010.7533

7. Lazaridis KN, Frank JW, Krowka MJ, Kamath PS: Hepatic hydrothorax: pathogenesis, diagnosis, and management. Am J Med. 1999, 107:262-7. 10.1016/s0002-9343(99)00217-x

8. John S, Paul MP, Murthy UK: An unusual presentation of cirrhotic pleural effusion in a patient with no ascites: a case report. Cases J. 2009, 2:6767. 10.4076/1757-1626-2-6767

9. Badillo R, Rockey DC: Hepatic hydrothorax: clinical features, management, and outcomes in 77 patients and review of the literature. Medicine (Baltimore). 2014, 93:135-42. 10.1097/MD.0000000000000025

10. Patil M, Dhillon SS, Attwood K, Saoud M, Alraiyes AH, Harris K: Management of benign pleural effusions 


\section{Cureus}

using indwelling pleural catheters: a systematic review and meta-analysis. Chest. 2017, 151:626-35.

10.1016/j.chest.2016.10.052

11. Runyon BA: Management of adult patients with ascites due to cirrhosis . Hepatology. 2004, 39:841-56.

10.1002/hep.20066

12. Ditah IC, Al Bawardy BF, Saberi B, Ditah C, Kamath PS: Transjugular intrahepatic portosystemic stent shunt for medically refractory hepatic hydrothorax: a systematic review and cumulative meta-analysis. World J Hepatol. 2015, 7:1797-806. 10.4254/wjh.v7.i13.1797 